\title{
Commentary on: Men and women show similar survival rates after breast cancer
}

\author{
Yin Pan $^{1} \cdot$ Ze-Zhou Song ${ }^{2}$
}

Received: 13 April 2017 / Accepted: 18 May 2017 / Published online: 8 June 2017

(C) Springer-Verlag Berlin Heidelberg 2017

To the editors: With great interests, we read the article by Prof. Bender et al. (2017), which concluded that there was no significant difference in prognosis between male and female breast cancer cases.

It is well known that the prognosis according to the survival rates between males and females breast cancer cases have been controversial (Gnerlich et al. 2011; Foerster et al. 2011) up to date. The hormone status could obviously affect estrogen receptor and progesterone receptor expression, which could lead to the large differences of estrogen receptor and progesterone receptor expression between male and female breast cancer cases (Yu et al. 2015). The comparison of the prognosis according to the survival rates between males and females breast cancer cases, therefore, is reasonable according to the different hormone statuses of women. That is to say, the prognosis according to the survival rates should be compared between males, post-menopausal women and pre/peri-menopausal women breast cancer cases. The results and conclusion of the study by Prof. Bender et al. (2017) should be carefully interpreted and further assessed.

This comment refers to the article available at doi:10.1007/s00432-016-2311-4.

An author's reply to this comment is available at doi:10.1007/s00432-017-2447-x.

Ze-Zhou Song

zezhou_song@126.com

1 Taizhou Central Hospital, Taizhou University Hospital, Taizhou, China

2 Department of Ultrasound, Zhejiang Provincial People's Hospital, \#158 Shangtang Road, Hangzhou, Zhejiang Province, China
Compliance with ethical standards

Conflict of interest The authors have no conflict of interest related to the manuscript.

\section{References}

Bender PMF, Oliveira LL, Costa CR et al (2017) Men and women show similar survival rates after breast cancer. J Cancer Res Clin Oncol 143:563-571

Foerster R, Foerster F, Wulff V et al (2011) Matched-pair analysis of patients with female and male breast cancer: a comparative analysis. BMC Cancer 11:335-348

Gnerlich J, Deshpande A, Jeffe DB et al (2011) Poorer survival outcomes for male breast cancer compared with female breast cancer may be attributable to in-stage migration. Ann Surg Oncol 18:1837-1844

Yu XF, Yang HJ, Yu Y et al (2015) A prognostic analysis of male breast cancer (MBC) compared with post-menopausal female breast cancer (FBC). PLoS ONE 10:e0136670 